\title{
Physical and Biological Satellite Observations of the Northwest African Upwelling: Spatial Extent and Dynamics
}

\author{
Anass El Aouni ${ }^{\circledR}$, Véronique Garçon ${ }^{\circledR}$, Joël Sudre ${ }^{\circledR}$, Hussein Yahia ${ }^{\circledR}$, Khalid Daoudi, and Khalid Minaoui
}

\begin{abstract}
The region along the North-West African coast $\left(20^{\circ} \mathrm{N}\right.$ to $36^{\circ} \mathrm{N}$ and $4^{\circ} \mathrm{W}$ to $\left.19^{\circ} \mathrm{W}\right)$ is characterized by a persistent and variable upwelling phenomenon almost all year round. In this article, the upwelling features are investigated using an algorithm dedicated to delimit the upwelling area from thermal and biological satellite observations. This method has been developed specifically for sea-surface temperature (SST) images, since they present a high latitudinal variation, which is not present in chlorophyll-a concentration images. Developing on the proposed approach, the spatial and temporal variations of the main physical and biological upwelling patterns are studied. Moreover, a study on the upwelling dynamics, which explores the interplay between the upwelling spatiotemporal extents and intensity, is presented, based on a 14-year time archive of weekly SST and chlorophyll-a concentration data.
\end{abstract}

Index Terms-Canary current system, chlorophyll-a, clustering, sea-surface temperature (SST), seasonal variability, upwelling.

\section{INTRODUCTION}

$\mathbf{T}$ HE Canary Current Upwelling System (CCUS) has its central part located off northwest African area (NWA); it is one of the planet's most productive marine ecosystems [1]. It belongs to the more extended NWA upwelling off Morocco, Mauritania, Gambia, and Senegal. Its exceptional productivity gives rise to large fish biomass dominated by small pelagic fish [2]. This continuous and variable upwelling phenomenon exists almost all year around [3]. The hydrodynamical process of the NWA upwelling is mostly forced by the equatorward trade winds that cause cold nutrient-rich intermediate waters to pump up [4], [5]. As a result, its main observable characteristic is the existence of a general surface current that operates along the coast from North to South, and the phenomenon can

Manuscript received May 12, 2019; revised August 8, 2019; accepted September 18, 2019. This work was supported by the French-Moroccan PHC-Toubkal under Project TBK/16-24 and Project PPR2-6. The work of J. Sudre and V. Garçon was supported by the Centre National de la Recherche Scientifique (CNRS). (Corresponding author: Anass El Aouni.)

A. El Aouni, H. Yahia, and K. Daoudi are with the INRIA Bordeaux Sud-Ouest, 33405 Talence, France (e-mail: anas.elaouni@gmail.com).

V. Garçon and J. Sudre are with the Centre National de la Recherche Scientifique (CNRS), Laboratoire d'Etudes en Géophysique et Océanographie Spatiales (LEGOS), 31400 Toulouse, France.

$\mathrm{K}$. Minaoui is with Laboratoire de Recherche Informatique et Télécommunications (LRIT) URAC 29, Faculty of Sciences, Mohammed V University, Rabat 10000, Morocco.

Color versions of one or more of the figures in this article are available online at http://ieeexplore.ieee.org.

Digital Object Identifier 10.1109/TGRS.2019.2946300 also be identified by seasonally variable cold and nutrient-rich waters in coastal areas [4], [5].

Some studies focused on the CCUS using the remotely acquired images of sea-surface temperature (SST). The SST images offer an overall view of the temperature distribution of the skin (first micrometers of the surface layer) of the surface ocean. These studies [3], [6]-[8] quantified the coastal cooling of the North-West African upwelling based on an SST-based upwelling index; this latter is computed as a thermal difference between the offshore and coastal waters. Other studies considered the coherent structures of the upwelling phenomenon, such as filaments, fronts, and eddies, and described their interannual variability [9]. Their finding shows that frontal interaction builds up across the entire coast: Cape Bojador $\left(26^{\circ} \mathrm{N}\right)$ with the maximum filament occurrence, followed by Capes Ghir $\left(31^{\circ} \mathrm{N}\right)$ and Blanc $\left(21^{\circ} \mathrm{N}\right)$. Others [10], [11] addressed the issue of the automatic identification of the northern part of the CCUS from the SST data. They used the fuzzy c-means (FCM) algorithm together with a threshold procedure to provide an automatic segmentation and extraction of upwelling regions on the SST images. This last approach has been modified and improved in [12]-[14] and applied to the southern part of the Moroccan Atlantic coast.

The variability of the upwelling in the CCUS was already studied in literature using the satellite images of ocean color. For instance, the connections between the $\mathrm{CHL}_{\mathrm{a}}$ concentration and the horizontal mixing computed from finite-size Lyapunov exponents were investigated in [15], and the finding shows a negative correlation between surface mixing and $\mathrm{CHL}_{\mathrm{a}}$ concentration. El Aouni et al. [16] investigated the connections between the later quantities over different capes along the north-west African upwelling; in their work, the horizontal mixing is computed based on the geodesic theory of Lagrangian coherent structures and their results show no clear connection between surface mixing and $\mathrm{CHL}_{\mathrm{a}}$ concentration. Lathuilière et al. [17] investigated CCUS seasonal and intraseasonal variations from $\mathrm{CHL}_{\mathrm{a}}$ concentration; satellite ocean-color data were used to describe the variations in $\mathrm{CHL}_{\mathrm{a}}$ concentration. This article identified three regions with various characteristics: the region between $\left(24^{\circ} \mathrm{N}-33^{\circ} \mathrm{N}\right)$, characterized by low upwelling seasonality and coastal $\mathrm{CHL}_{\mathrm{a}}$; the region between $\left(19^{\circ} \mathrm{N}-24^{\circ} \mathrm{N}\right)$, distinguished by a moderate upwelling seasonality and an ongoing major offshore extent of $\mathrm{CHL}_{\mathrm{a}}$; and the region between $\left(10^{\circ} \mathrm{N}-19^{\circ} \mathrm{N}\right)$, characterized 
by intense upwelling seasonality and strong offshore extent. Pradhan et al. [18] described the seasonal and interannual changes in $\mathrm{CHL}_{\mathrm{a}}$ concentrations in the Mauritanian upwelling and reported the anomalous event that occurred in CCUS during 1998/1999 in terms of the ENSO index. Arístegui and Montero [19] studied the CCUS spatiotemporal changes of phytoplankton biomass and respiration, which was to a great extent explained by hydrographic changes at the mesoscale level. Menna et al. [20] used five years of different satellite observations and surface drifters to describe the upwelling seasonality along the coasts of Mauritania and Senegal. Their results allowed them to reveal the period of upwelling-favorable winds in different geographical sectors, to emphasize the different behaviors between different sectors and to describe the westward transport of cold water.

The variability in the upwelling was studied using the $\mathrm{CHL}_{\mathrm{a}}$ concentration in other global ocean upwelling systems as the Benguala [21] and Peru [22]. Demarcq et al. [21] studied the fluctuations of phytoplankton biomass in the Benguela ecosystem over an eight-year period of time using a $\mathrm{CHL}_{\mathrm{a}}$ index. They estimated the $\mathrm{CHL}_{\mathrm{a}}$ index as the integration of the $\mathrm{CHL}_{\mathrm{a}}$ concentration from the coast to an offshore minimum level of $1 \mathrm{mg} \mathrm{m}^{-3}$. Results show that their studied system can be divided into two major sectors, north and south of the Luderitz upwelling cell with a clear and more contrasting seasonal pattern. Nixon and Thomas [22] used two years of satellite $\mathrm{CHL}_{\mathrm{a}}$ to estimate the size of the productive habitat related to the upwelling of Peru by using the $1-\mathrm{mg} \mathrm{m}^{-3}$ threshold limit. Results show maximum areas varying from $120 \times 103 \mathrm{~km}^{2}$ to $220 \times 103 \mathrm{~km}^{2}$. Belkin and O'Reilly [23] proposed an algorithm to detect oceanic fronts from different oceanic observations. Their algorithm is universal with regard to regions and variables such as $\mathrm{CHL}_{\mathrm{a}}$ and SST and SSH images. Frontal maps generated by their algorithm are freely available at NOAA.

In this article, a study with a twofold objective to investigate the spatial extent and the dynamics of the CCUS is presented. First, a novel approach for the segmentation of the upwelling areas along the central part of the Canary Upwelling Ecosystem is presented using an automatic delimitation of the upwelling areas from the SST and $\mathrm{CHL}_{\mathrm{a}}$ images. Various techniques have been proposed for the subject of the upwelling detection and delimitation for different upwelling ecosystems. However, none of the previous work has successfully been able to delineate the central part of the Canary Upwelling Ecosystem from the SST images [12]-[14], [24], [25]. The proposed method is capable of extracting upwelling regions from the SST and $\mathrm{CHL}_{\mathrm{a}}$ images.

One main advantage of the proposed approach is that it allows the characterization of the same upwelling phenomenon from physical and biological observations. It does identify the upwelling as regions of homogeneous $\mathrm{CHL}_{\mathrm{a}} /$ temperature, rather than defining a noncontinuous front or setting a threshold limit that is not natural considering a dynamical system. Second, the CCUS spatial distribution is studied from these observations along with their fluctuations from seasonal to interannual time scales. Finally, the upwelling variability is explored from its spatiotemporal extents and different

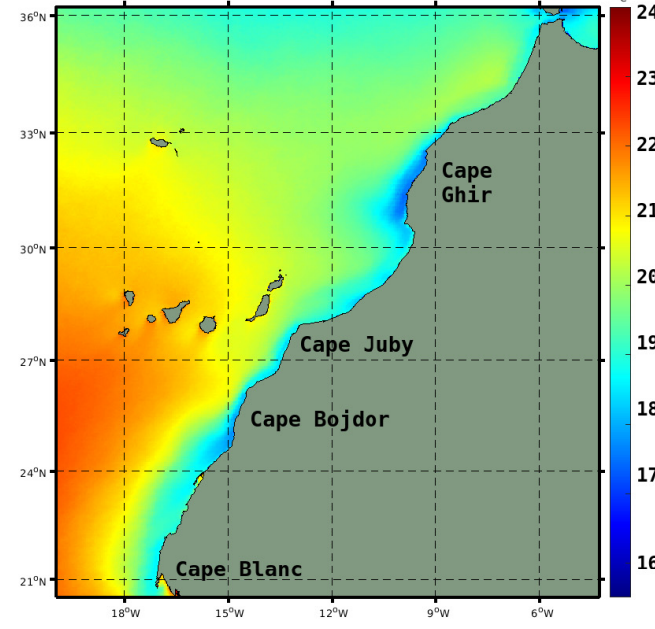

a)

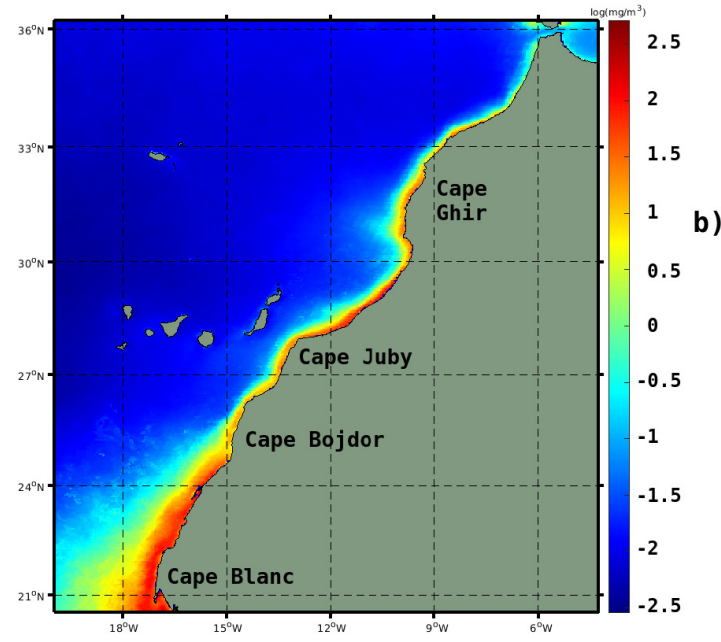

Fig. 1. Climatological means of (a) SST image $\left({ }^{\circ} \mathrm{C}\right)$ and (b) $\mathrm{CHL}_{\mathrm{a}}$ concentration $\left[\log \left(\mathrm{mg} / \mathrm{m}^{3}\right)\right]$ image for the period $2003-2016$.

upwelling indices to have an overall picture of its dynamics. The presentation is structured as follows: Section II presents the area of interest and the database used throughout this article. Section III describes the methodology used to identify the upwelling areas and the upwelling indices used to throughout this article, while Section IV reports the experimental results and analysis before a conclusion in Section V.

\section{DATA AND AREA OF INTEREST}

This article focuses on the north-western part of the CCUS (from $20^{\circ} \mathrm{N}$ to $36^{\circ} \mathrm{N}$ and $4^{\circ} \mathrm{W}$ to $19^{\circ} \mathrm{W}$ ). This zone is depicted in Fig. 1, which shows two climatological images (SST and CHL C $_{\text {) }}$ of the same area. MODIS-T SST and $\mathrm{CHL}_{\mathrm{a}}$ data are obtained from NASA's oceancolor website http://oceancolor.gsfc.nasa.gov/ with a spatial resolution of $4 \mathrm{~km} \times 4 \mathrm{~km}$. Data sets consisting of 644 eight-day SST and 644 eight-day $\mathrm{CHL}_{\mathrm{a}}$ images are used, covering the period between 2003 and 2016. The images in Fig. 2 display typical upwelling conditions with a well-defined upwelling main front in terms of sharpness all over the studied area visible on the $\mathrm{CHL}_{\mathrm{a}}$ image. The SST image presents a well-defined upwelling main front only south of $28^{\circ} \mathrm{N}$, the thermal front 


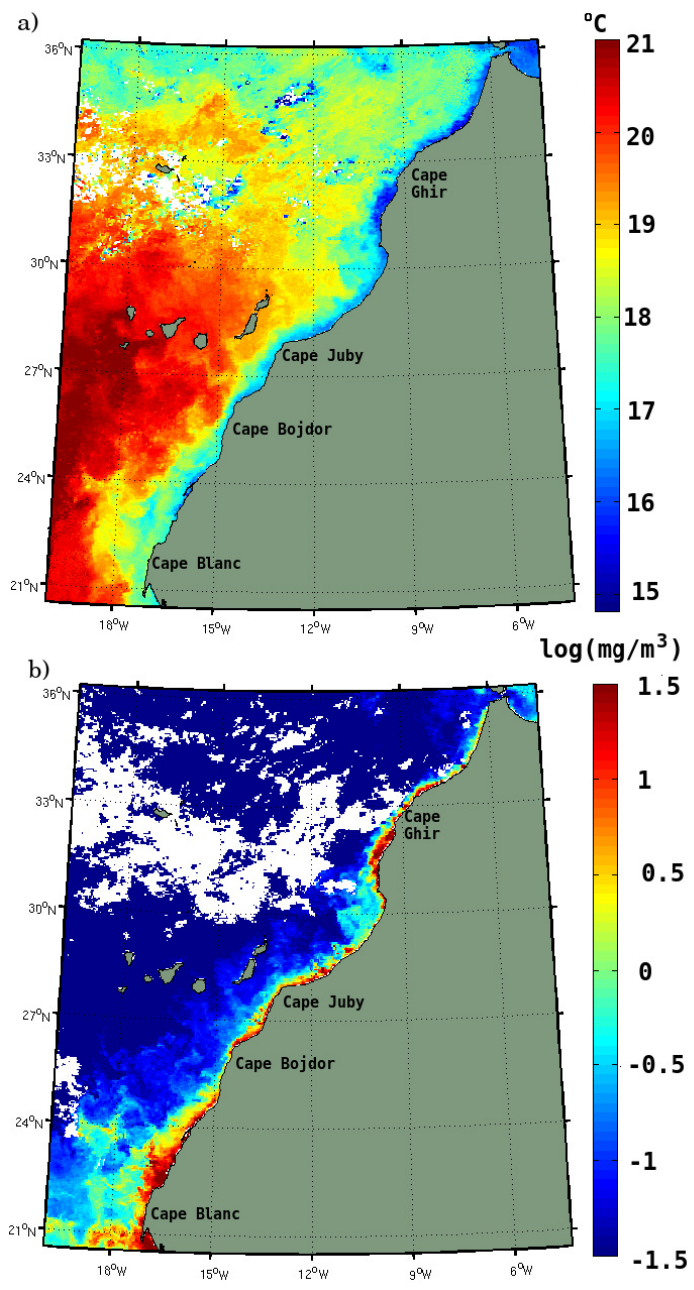

Fig. 2. (a) Eight-day SST image $\left({ }^{\circ} \mathrm{C}\right)$ and (b) $\mathrm{CHL}_{\mathrm{a}}$ concentration $\left[\log \left(\mathrm{mg} / \mathrm{m}^{3}\right)\right]$ image obtained on the first week of January 2007 , showing a typical upwelling scenario from physical and biological observations; similar oceanic structures appear in both the images.

being not clearly identified north of $28^{\circ} \mathrm{N}$. Moreover, the temperature distribution varies both meridionally and zonally, whereas the $\mathrm{CHL}_{\mathrm{a}}$ distribution shows only clear longitudinal variation. Both the images are acquired on the same date (first week of January 2007). The CHLa image shows more cloudiness than what is present in the thermal observation. This is due to different wavelengths and algorithms used to provide such data. Eight-day SST and $\mathrm{CHL}_{\mathrm{a}}$ images are considered, because they constitute a good compromise between the variability of the pixel values and the necessity to provide a continuous spatiotemporal coverage. SST and $\mathrm{CHL}_{\mathrm{a}}$ images are included in the database if they have at least $25 \%$ of valid information in the area between the coast and $200-\mathrm{km}$ offshore. Monthly SST and CHLa images are also considered to describe the interannual variability of the upwelling dynamics. The daily global $1 / 4^{\circ}$ resolution product Geostrophic and Ekman Current Observatory (GEKCO) of the surface currents developed in [26] is also used to compute the eddy kinetic energy and the cross-shore Ekman Transport index. The surface currents are calculated from a combination of wind-driven Ekman currents, at 15-m depth, derived from the
QuikSCAT and ASCAT wind estimates, and the geostrophic currents computed from sea-surface heights.

\section{METHODS}

\section{A. Upwelling Identification and Segmentation}

The goal of this article is to develop an upwelling segmentation method that allows the identification and extraction of the upwelling areas from the SST and CHLa images. First, the method seeks to overcome the problems encountered when applying the method developed in [14] over the SST images, and to provide an upwelling segmentation from biological observations. The approach developed in [14] consists of two steps: first, applying a clustering algorithm over the SST images with a number of clusters $c=2$ in order to separate the upwelling cold waters from the warmer ones offshore and then labeling the cluster with the minimal centroid as upwelling waters. However, the outputs of the first step include isolated structures in the offshore waters. Since that all the segmented pixels belonging to the upwelling must have connectivity with the coastline, Tamim et al. [14] used the region-growing algorithm [27] to remove noisy structures in the offshore water. This algorithm aims at grouping a set of pixels according to the homogeneity and adjacency criteria. The latter method gives satisfying results in the southern region, where the upwelling main front is sharp. However, it fails to properly recognize the areas of upwelling belonging to the northern part, as shown in Fig. 3(b). Fig. 3(b) shows that the method completely overestimates the contouring of the upwelling region in the northern part. The main reason behind this failure lies in the concept itself along with the high variability of the latitudinal distribution of temperatures. Hence, for example, northern offshore temperatures can be close to the southern upwelling temperatures [see Fig. 3(a)] (blue circles highlight the same temperature; in the north, it presents offshore water, while it is considered as upwelling in the south). Fig. 3(c) shows the phenomenon of latitudinal high variability of temperature. In Fig. 3(c), the orange line illustrates the role of the FCM algorithm (considered as a linear clustering method), which separates the two clusters (upwelling and nonupwelling), and this figure shows that a part of the green curve falls in the cluster presenting the upwelling water. As stated above, north and central maximal temperatures can be much lower than the minimal temperatures in the south. Thus, a possible way to identify the upwelling regions over this upwelling system is to consider a subregion approach, where the whole system has to be divided zonally into subregions, then apply the method developed here [14] over each subregion, and finally merge all the regions later on. An example is given in Fig. 3(d), where the green curve represents the maximal temperature at each latitudinal step of the SST image in Fig. 3(a). To separate the green curve from the blue one fully, the system was divided into four subregions. This figure shows that the subregions have different sizes. The problem is how to define these subregions, knowing that the upwelling itself varies seasonally. For each SST image, a different number of subregions will be found. The solution to this is as follows. 


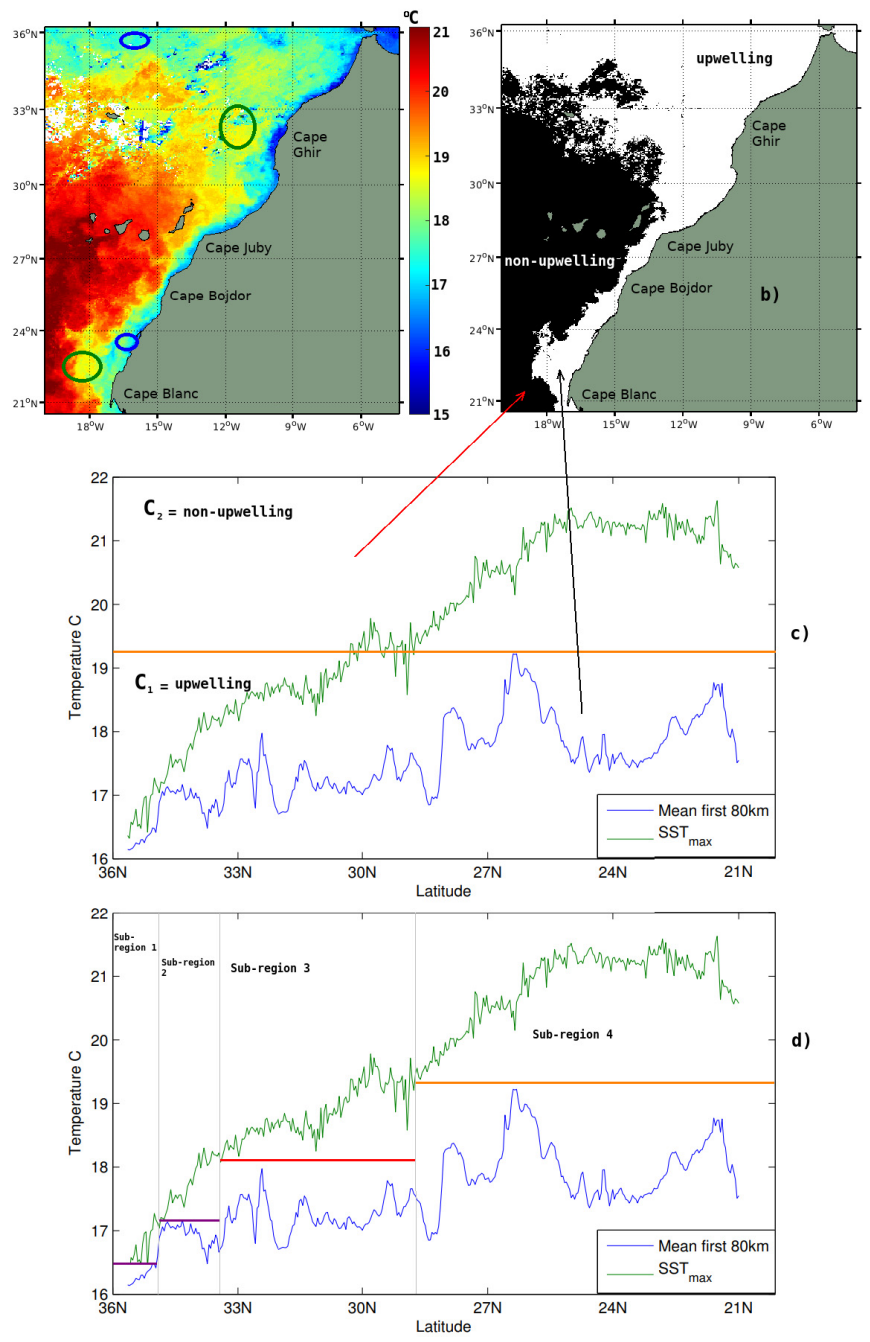

Fig. 3. (a) Eight-day SST images obtained on the first week of January 2007, with thermal comparison between the inshore and offshore waters (circles with same the color highlight similar temperature caught in the offshore and the upwelling waters). (b) Result of the method developed in [14] applied to the SST image from Fig. 3(a). White color refers to the upwelling water, while black color refers to the offshore water. (c) and (d) Latitudinal comparison between the upwelling and the offshore temperature; the green curve represents the maximal temperature on each latitudinal step of the SST image in Fig. 3(a) and the blue curve represents the mean temperature over the first $80 \mathrm{~km}$ of each latitudinal step.

1) Zonally divide the system into subregions characterized by a low latitudinal variation of temperature.

2) Over each one of the subregions, apply the technique developed in [14].

3) Later on, merge the results of each subregion to have a final delineation of the upwelling limit.

However, this could result in a discontinuity of the main upwelling contour (knowing that upwelling waters in each subregion will have its own centroid). To overcome this, this article proposes the following.

1) First, apply clustering algorithm with a maximal number of clusters over the whole system.

2) Zonally divide the system into subregions.

3) In each subregion, identify the upwelling water.

4) Later on, merge the upwelling region from the subregion to reproduce the main upwelling contour.

1) Extraction of the Upwelling Areas: In the unsupervised clustering, the number of clusters is rarely known a priori and it has to be selected with great care. In fact, if the cardinality (the number of pixels belonging to a given cluster) of a cluster is larger, one or more good compact clusters should be broken due to the variations in the similarity, or if it is smaller, several clusters may be merged [28]-[30]. In the literature, two main techniques can be distinguished to decide the good number of clusters in data as follows.

1) Use the cluster validity functions to extract the good number of clusters, which best describe the data.

2) Start with a large number of clusters and decrease this number progressively by merging similar clusters, as indicated by some predefined criteria.

In this article, the second approach is used, but instead of using the similarity-based cluster merging approach, an upwelling special algorithm that merges parts of clusters, which best reproduce the shape of upwelling, is developed. The proposed method is based on a rigorous analysis of the spatial distribution of the upwelling; the particle swarm optimization (PSO) clustering algorithm [31], [32] is applied with a maximal number of clusters $C_{\max }=6$ over one year 
of SST images. Then, the meridional and zonal distributions of the clusters are analyzed. Results show the following.

1) The cardinality of the clusters gets smaller in the southern direction, which results in upwelling with more clusters in the southern part than the northern one.

2) The same cluster presents the upwelling water in the southern region and the offshore water in the northern region.

3) The same cluster shows smaller cardinality in the upwelling water and a larger one in the offshore water.

4) Starting from the coastline, the cardinality of the clusters gets larger in the offshore direction (the upwelling waters present a small portion compared with the waters in the open ocean).

Based on this analysis, an algorithm that iteratively breaks and merges parts of clusters to create the upwelling pattern of the studied area is developed. The algorithm initializes the PSO clustering algorithm with a number of clusters $C_{\max }=6$. [Fig. 4(a) (top) shows the results from the PSO clustering algorithm applied on the SST image from Fig. 2, whereas Fig. 4(a) (bottom) shows the results from the PSO clustering algorithm applied on the $\mathrm{CHL}_{\mathrm{a}}$ image from Fig. 2.] Then, the algorithm starts by zonally dividing the whole system into equally small subregions of $90 \mathrm{~km}$ : for each subregion from north to south, it starts from the coastline and calculates the cardinality of the first cluster and labels it as upwelling if it presents less than $15 \%$ of cardinality of the subregion, and then goes to the next one, and includes it only if the cardinality of the current cluster is less than or equal to the sum of the previous ones, as described by Algorithm 2 (Appendix). Each subregion is characterized by the number of clusters it includes. Fig. 4(b) shows the result of Algorithm 2. Gray lines mean that only one cluster is considered, for the brown lines, two clusters are considered, three for the green, and four for the white.

The second part of the algorithm consists of merging connected subregions of similar number of clusters in order to create the different upwelling regions with different number of clusters (isolated subregions add or remove one cluster depending on their surrounding).

Finally, four regions are defined [see Fig. 4(c)]: the first one contains only one cluster, the second contains two, three for the third, and four for the last one.

Fig. 4(d) shows the final segmentation obtained for the upwelling regions. Finally, these regions are merged to create the upwelling area, as shown in Fig. 4(e). The results shows that the proposed method yields a very accurate segmentation on the whole coast.

\section{B. Thermal-Based Upwelling Index}

Thermal-based upwelling index $I_{T}$ is computed as a simple thermal difference between the warm offshore waters and the cool upwelling water [3] as follows: if $r$ is a given latitude, $T_{\max }^{r}$ and $T_{\min }^{r}$ are the maximal offshore and minimal inshore temperatures, respectively, and then, the upwelling index at latitude $r$ is:

$$
I_{c}^{r}=T_{\max }^{r}-T_{\min }^{r}
$$

On the other hand, note that by definition, $T_{\min }^{r}$ necessarily belongs to the upwelling region. Thus, given the developed upwelling segmentation method, naturally, $T_{\min }^{r}$ is defined as the minimal temperature recorded within the extracted upwelling area. That is, let $S$ be the segmented upwelling area, and then, given a radial $r \in\{1, \ldots, R\}$ composed of temperature pixels $r=\left\{T_{i}^{r} ; i=1, \ldots, R\right\}, T_{\min }^{r}$ is defined as

$$
T_{\min }^{r}=\min _{i \in S} T_{i}^{r} \text {. }
$$

Fig. 4(f) shows an example of a radial within which $I_{c}$ is computed; $\mathrm{SST}_{\min }$ is sought within the red line, while $\mathrm{SST}_{\max }$ is within the blue line.

\section{CHL Index}

The $\mathrm{CHL}_{\mathrm{a}}$ index $I_{C}$ is defined as the integration of the $\mathrm{CHL}_{\mathrm{a}}$ concentration from the coastline to the limit of the extracted upwelling contour. This is similar to the product of the average $\mathrm{CHL}_{\mathrm{a}}$ concentration and the upwelling extent (upwelling limit) over the same radial and can be expressed in $\mathrm{mg} \mathrm{m}^{-3} \times \mathrm{km}$.

\section{Cross-Shore Ekman Transport}

The cross-shore Ekman transport $\left(I_{\mathrm{CSET}}\right)$ is defined as the water flux theoretically transported offshore by the wind stress (from satellite data) from the coastal upward flux of colder water. It is computed using daily wind measurements from the QuikSCAT and ASCAT winds at $1 / 4^{\circ}$ resolution. By assuming a coastal balance between the Coriolis effect and the coastal wind stress, the offshore Ekman transport per unit length $(v$, in the zonal direction) can be expressed by

$$
v=\frac{\tau_{y}}{\rho f}
$$

This index evaluates the volume of upwelled flow. This transport depends on wind stress and Coriolis force $f$, where $\tau_{y}$ is the coastal (in the meridional direction) surface wind stress and $\rho$ is the density of surface water.

\section{E. North Atlantic Oscillations}

One of the Northern Hemisphere's most important teleconnection indices (NAO) has been obtained from the National Center of Environmental Prediction (NCEP) at monthly time scales from 2003 to 2016. This mode has shown to be the most prevalent pattern on the eastern North Atlantic region. It is made up of a north-south dipole of geopotential anomalies with a center located in Iceland and another one spanning between $35^{\circ} \mathrm{N}$ and $40^{\circ} \mathrm{N}$ in the central North Atlantic. A positive phase on this index is an augmentation in the pressure differences; as a result, frequency and strength of winter storms increase across the Atlantic Ocean that typically take a more northerly track [33], [34]. The negative phase represents a reduced pressure gradient, resulting in a weak and small amount of winter storms across Europe, which travels on a more westeast pathway. Research has identified the NAO index as the local manifestation of the more global pattern of the Arctic Oscillation during the winter [35]. 

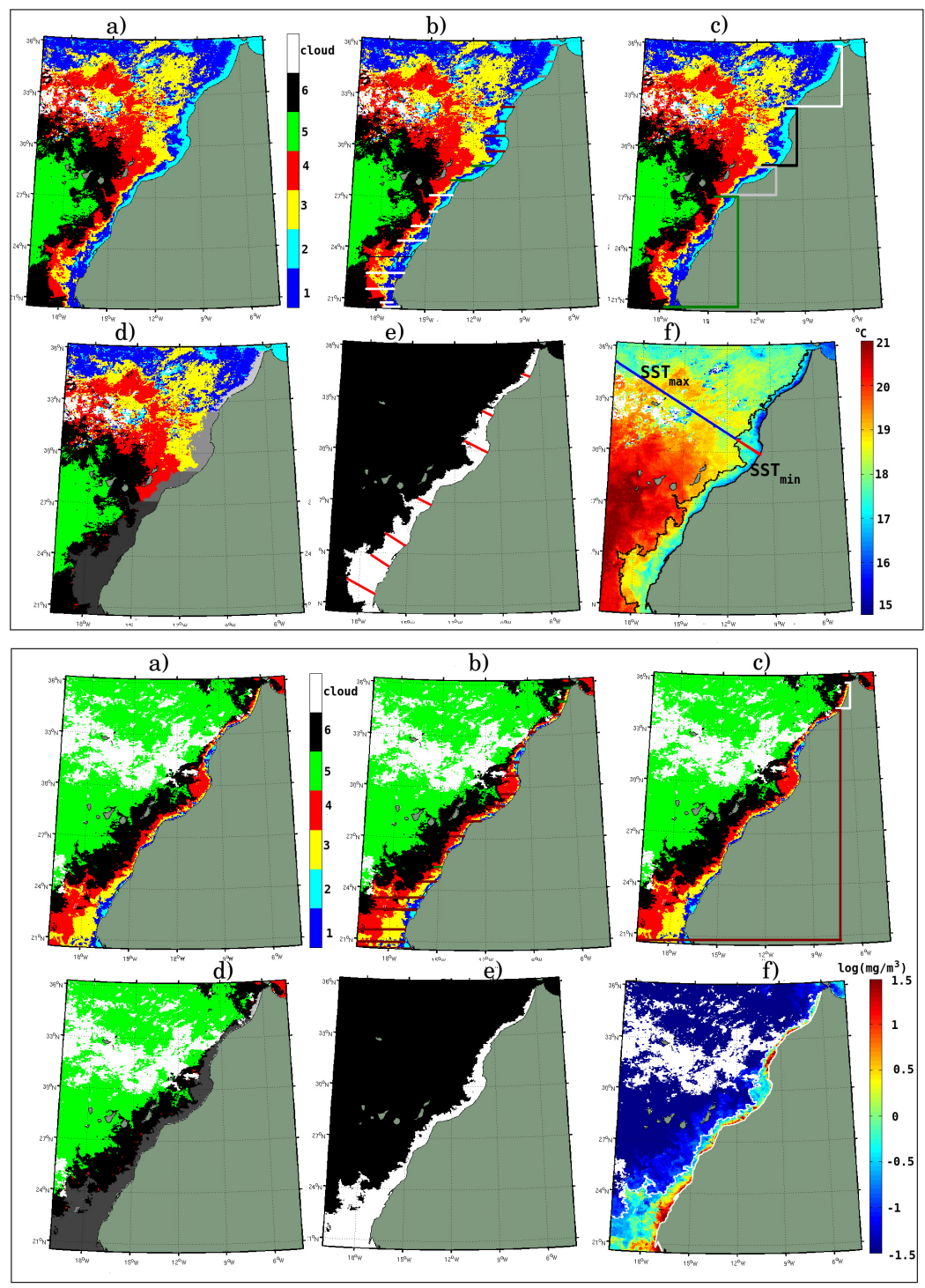

Fig. 4. (a) PSO clustering applied to SST (top) $\mathrm{CHL}_{\mathrm{a}}$ (bottom). (b) Result of Algorithm 2. (c) Subregions of the connected groups of pixels with the same number of candidate clusters. (d) Different upwelling regions. (e) Binary image of the proposed method. (f) Final segmentation achieved by the proposed method. The line (black for SST and white for CHLa) shows the delimitation of the upwelling area.

\section{SEASONAL AND INTERANNUAL UPWELLING VARIABILITY}

The proposed method is used to provide a seasonal climatology and to document the interannual variability of the African upwelling extent from the SST and $\mathrm{CHL}_{\mathrm{a}}$ imageries. For each latitudinal step, the upwelling extent is calculated as the length of the radial starting from the coastline and ending in the extracted contour of upwelling. Fig. 4(e) (Top) shows an example of this calculation.

\section{A. Spatiotemporal Variability of the Upwelling Extent From SST and $\mathrm{CHL}_{a}$ Imageries}

The seasonal variability of the upwelling extent from the SST and CHL $\mathrm{C}_{\mathrm{a}}$ images is discussed based on the Hövmoller diagrams at $4-\mathrm{km} / 8$-day spatiotemporal resolution. Fig. 5 shows the Hövmoller diagram of the seasonal climatology of the upwelling extent from the SST and $\mathrm{CHL}_{\mathrm{a}}$ images, computed for the period 2003-2016.

The main patterns of variability are synthesized into four characteristic regions: region south of $25^{\circ} \mathrm{N}$ (between Cape Bojdor and Cape Blanc) with maximal extent, followed by the region of Cape Ghir $\left(31^{\circ} \mathrm{N}\right)$ with maximal extent occurring during summer; and the region between $31^{\circ} \mathrm{N}$ and $25^{\circ} \mathrm{N}$ (between Cape Bojdor and Cape Ghir) with minimal extent and north of $33^{\circ} \mathrm{N}$ (north of Cape Ghir) with weak extent during summer and absent in winter. Both the upwelling extents from the SST and $\mathrm{CHL}_{\mathrm{a}}$ images show slightly similar patterns, with a general increase in the upwelling extent deduced from $\mathrm{CHL}_{\mathrm{a}}$ south of $25^{\circ} \mathrm{N}$. Both the parameters are mostly driven by the same process, which is the wind stress applied at the sea surface, but the spatiotemporal evolution can be controlled by other mechanisms. The thermal ocean response can be instantaneous to the wind stress, but the biological response in terms of $\mathrm{CHL}_{\mathrm{a}}$ richness can be lagged. In addition, the $\mathrm{CHL}_{\mathrm{a}}$ 
a)

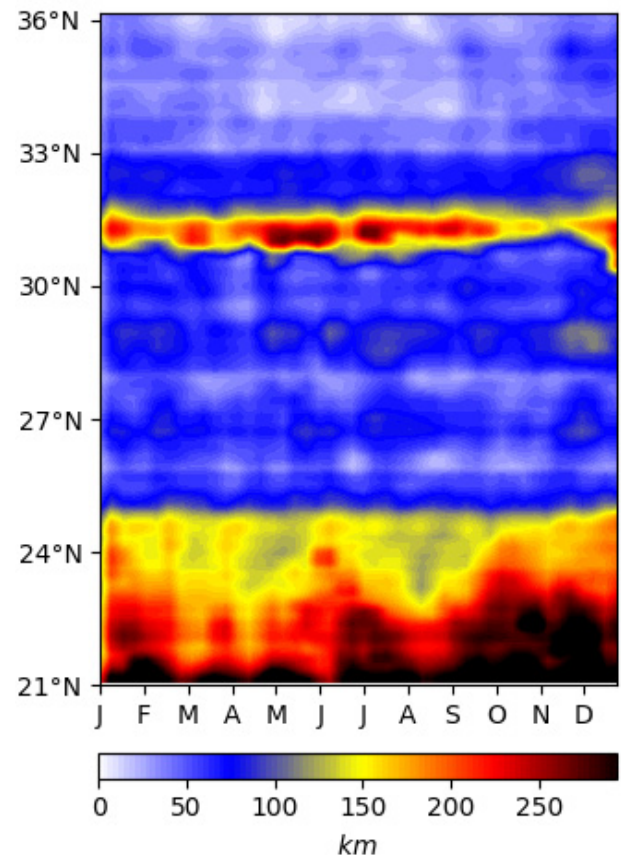

b)

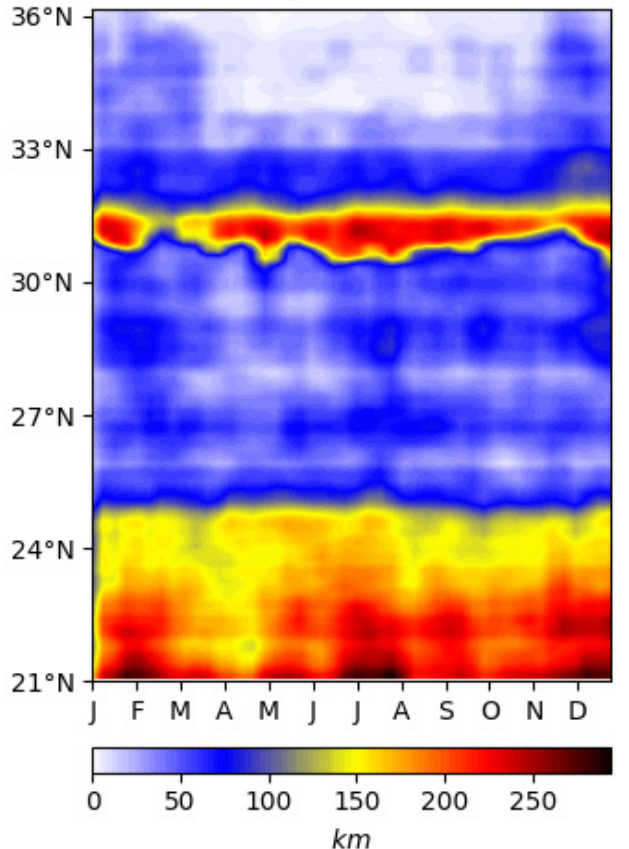

Fig. 5. Space-time Hövmoller plots of upwelling seasonal variability of (a) CHLa extent and (b) SST extent for the period $2003-2016$.

extent can potentially lead to the importance of filaments in transporting water masses offshore and their physical and biological characteristics across the shelf break.

In the southern part of the system (south of $23^{\circ} \mathrm{N}$ ), Kostianoy and Zatsepin [36] reported that filaments are responsible for $50 \%$ of the upwelled waters to flow across the upwelling front. The alongshore variations of eddy kinetic energy were analyzed in order to study the potential role of mesoscale dynamics. Fig. 6(e) shows the log of the eddy kinetic energy computed along the studied area. Progressing south, the EKE obviously increases along the coast. The CHLa extent width may increase southward caused by an increase in the horizontal stirring caused by mesoscale processes. Note that the nature of mesoscale processes can differ, such as coastal and planetary waves, baroclinic instabilities of the upwelling jet, and the fact that wind stress and mesoscale dynamics are connected and cannot be viewed as separate processes.

\section{B. Interannual Variability of the Upwelling Dynamics}

In this section, the spatiotemporal dynamics of the north-west African upwelling is explored throughout various physical and biological upwelling indices.

Fig. 6(a) and (b) shows the Hövmoller diagrams at 4-km/30-day spatiotemporal resolution of the upwelling extent from the SST and CHLa images, while Fig. 7(a) and (b) shows their anomalies.

The offshore extent of the upwelling, as determined from the SST images [see Fig. 6(b)], displays high variability both in space and time, with quasi-permanent greater extents $(>150 \mathrm{~km})$ in the region between Cape Bojdor and Cape Blanc $\left(21^{\circ} \mathrm{N}-25^{\circ} \mathrm{N}\right)$, in summer around $31^{\circ} \mathrm{N}$ (Cape Ghir) during most years. The region between $31^{\circ} \mathrm{N}$ and $25^{\circ} \mathrm{N}$ is characterized by a very moderate average offshore extent of the upwelling $(<80 \mathrm{~km})$. Finally, the northern part of the system (north of $33^{\circ} \mathrm{N}$ ) records the lowest upwelling extent not exceeding $50 \mathrm{~km}$ in summer and absent in winter. On the other hand, the upwelling extent as determined from $\mathrm{CHL}_{\mathrm{a}}$ concentrations shows a very similar pattern to the one from SST, with a large extent in the biological observations, suggesting that the response of the phytoplankton to upwelling processes may extend beyond the main physical frontal zone. The $\mathrm{CHL}_{\mathrm{a}}$ front extended up to $400 \mathrm{~km}$, compared with $300 \mathrm{~km}$ for the SST front in the south between $24^{\circ} \mathrm{N}$ and $21^{\circ} \mathrm{N}$. However, both the fronts were closer to the coast and also closer to each other in the central region between $25^{\circ} \mathrm{N}$ and $33^{\circ} \mathrm{N}$. For the region north of $33^{\circ} \mathrm{N}$, the extent of the upwelling from biological observation is more pronounced than the thermal one, which is absent in winter during most years. The greater offshore extent of the $\mathrm{CHL}_{\mathrm{a}}$ front in the southern region could be understood by the flow pattern of the Canary Current. The current flows near the coast in the north but moves farther offshore south of $24^{\circ} \mathrm{N}$ along with mesoscale processes, which possibly advect the phytoplankton beyond the SST front to considerable distances offshore in the south. In terms of interannual variability, the whole period of time is characterized by a considerable year-to-year variability and oscillations between periods of strong and weaker upwelling extent. Nevertheless, such separation is very area-dependent (see Fig. 7).

Along with the upwelling extent, three upwelling indices are used for our analysis, which are computed at every latitude and each time step of the interannual variability: thermal-based upwelling index $I_{T}$, the $\mathrm{CHL}_{\mathrm{a}}$ index $I_{C}$, and the cross-shore Ekman transport $\left(I_{\mathrm{CSET}}\right)$. 
a)

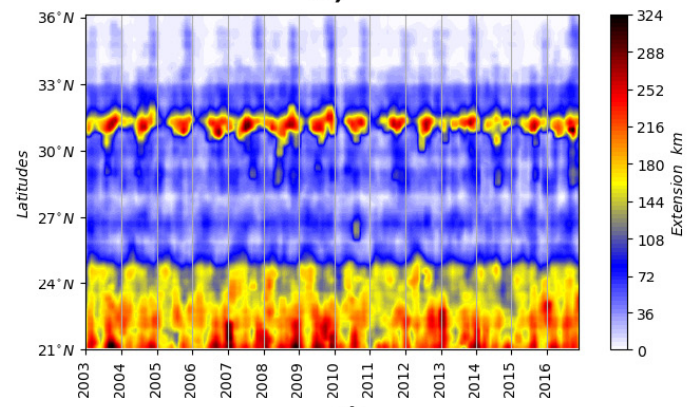

c)

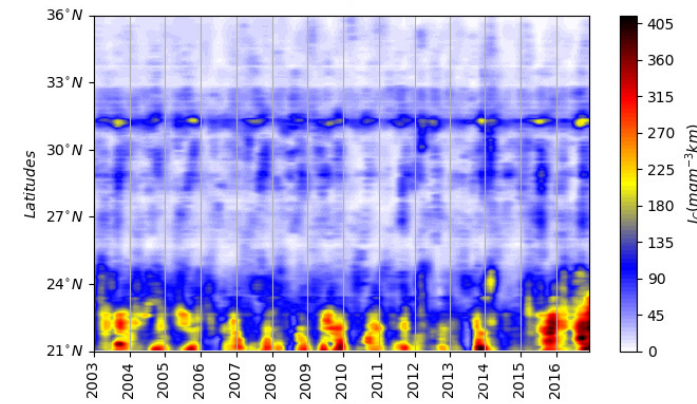

e)

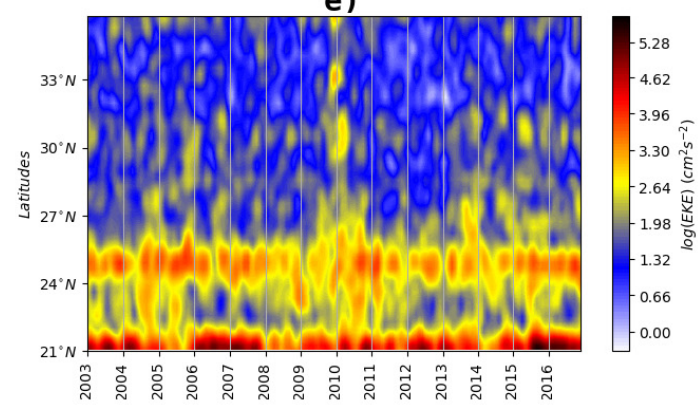

b)

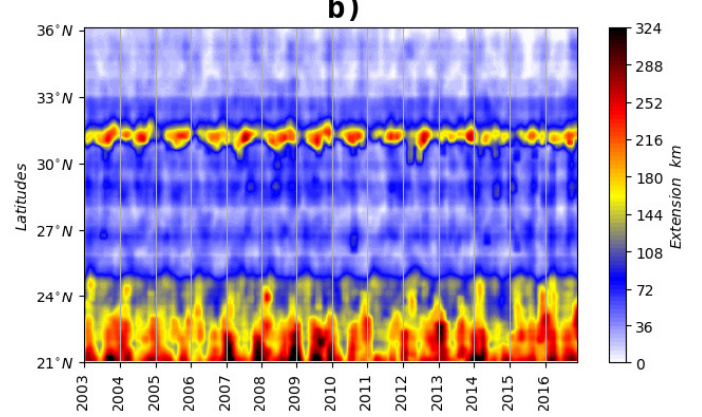

d)

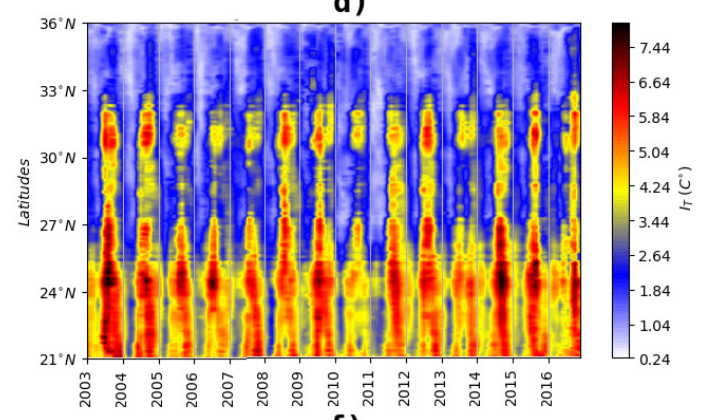

f)

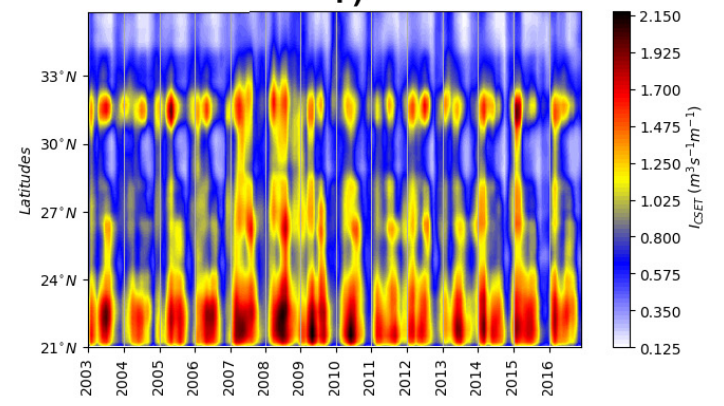

Fig. 6. Space-time Hövmoller diagram of (a) upwelling extent from SST, (b) upwelling extent from $\mathrm{CHL}_{\mathrm{a}}$, (c) upwelling index ( $I_{c}$ ) computed as the $\mathrm{CHL}_{\mathrm{a}}$ average multiplied by its extent, (d) upwelling intensity $I_{T}$, (e) eddy kinetic energy $\left(\mathrm{cm}^{2} \mathrm{~s}^{-2}\right.$ ) estimated from geostrophic velocities derived from satellite-derived sea-surface height anomalies, and (f) cross-shore Ekman transport ( $I_{\mathrm{CSET}}$ ), over the $2003-2016$ period.

Here, the interannual variability of the upwelling intensity is analyzed. Fig. 6(d) shows an Hövmoller diagram at a 4-km/30-day spatiotemporal resolution of upwelling intensity $I_{T}$. The main patterns of variability can be synthesized into the three characteristic regions.

1) The northern region between $33^{\circ} \mathrm{N}$ and $36^{\circ} \mathrm{N}$ where the upwelling is weak/inexistent. This is consistent with the presence of weaker and unfavorable orientation of the winds in this region (winds are not parallel to the coastline).

2) The central region between $27^{\circ} \mathrm{N}$ and $33^{\circ} \mathrm{N}$. Here, the upwelling is stronger in summer and autumn, with the highest values around the locations where prominent upwelling filaments are developed at Cape Juby $\left(27^{\circ} \mathrm{N}\right)$ and Cape Ghir $\left(31^{\circ} \mathrm{N}\right)$.

3) The southern Moroccan region between $21^{\circ} \mathrm{N}$ and $27^{\circ} \mathrm{N}$, where the upwelling is intense throughout the year with a maximum from spring to autumn but a decrease in intensity occurs in some years, such as in 2010, where the North Atlantic Oscillation reaches extreme negative values (see Fig. 8).

Indeed, the upwelling intensity $I_{T}$ decreases from south to north, whereas intensities vary roughly between $4{ }^{\circ} \mathrm{C}$ and $8{ }^{\circ} \mathrm{C}$ in the south, $2{ }^{\circ} \mathrm{C}$ and $6{ }^{\circ} \mathrm{C}$ in the center, and below $2{ }^{\circ} \mathrm{C}$ in the north. Moreover, there is a clear periodicity in the seasonal variability showing a weak/absent upwelling in winter, which increases through the year to reach its highest value in summer.

In order to interpret the seasonal variability of the upwelling intensity $I_{T}$, the focus goes toward another proxy of the upwelling index, the Cross-shore Ekman Transport ICSET [see Fig. 6(f)]. It shows that the main pattern of the upwelling-favorable winds occurred during January-October for the region south of $24^{\circ} \mathrm{N}$ with a minimum marked in at the end of each year. Such winds occur north of $24^{\circ} \mathrm{N}$ mostly during March-July and marked a minimum mostly between August and December for most years. Latitudinal variations are clearly identified: ICSET peaks around $31^{\circ} \mathrm{N}$ and between $27^{\circ} \mathrm{N}$ and $21^{\circ} \mathrm{N}$. These peaks are located off capes, suggesting that orographic effects accelerate the wind locally. At large scale, $I_{\mathrm{CSET}}$ and upwelling intensity $I_{T}$ show similar patterns, with a time lag spatially varying meridionally between four and six weeks. Moreover, upwelling intensity and $I_{\mathrm{CSET}}$ span almost the same seasons on the three regions with nearly coincident maxima and minima proportionally, clearly suggesting that the seasonal and latitudinal variabilities of $I_{T}$ are operated by changes in the trade winds. 
a)

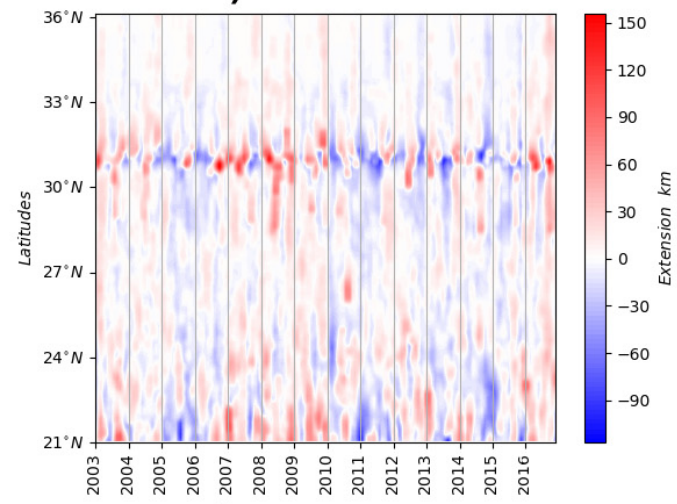

c)

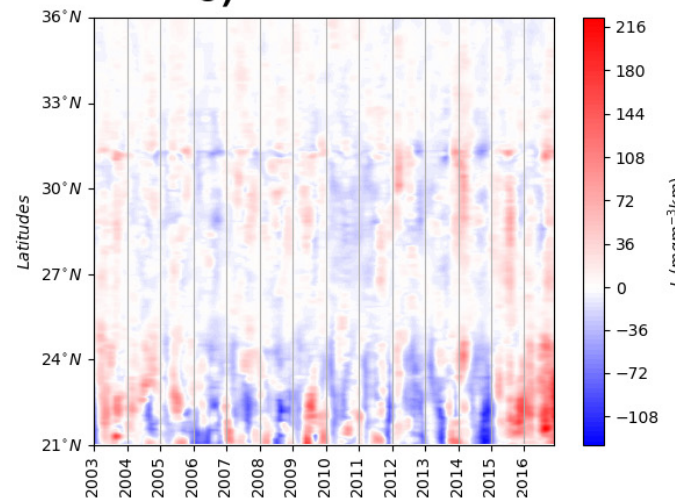

e)

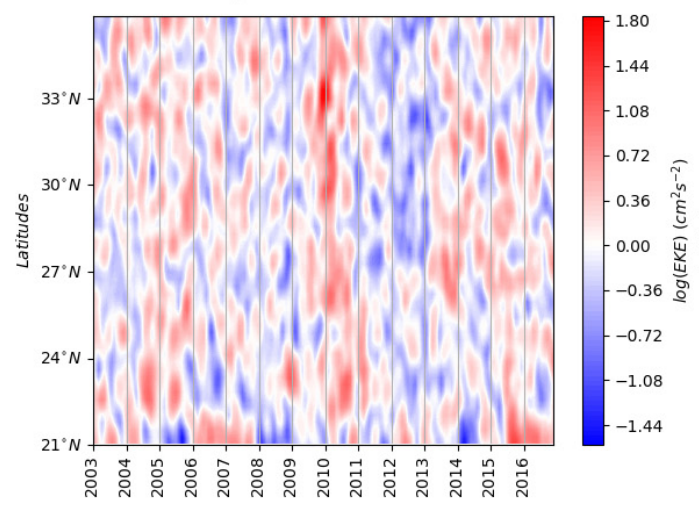

b)

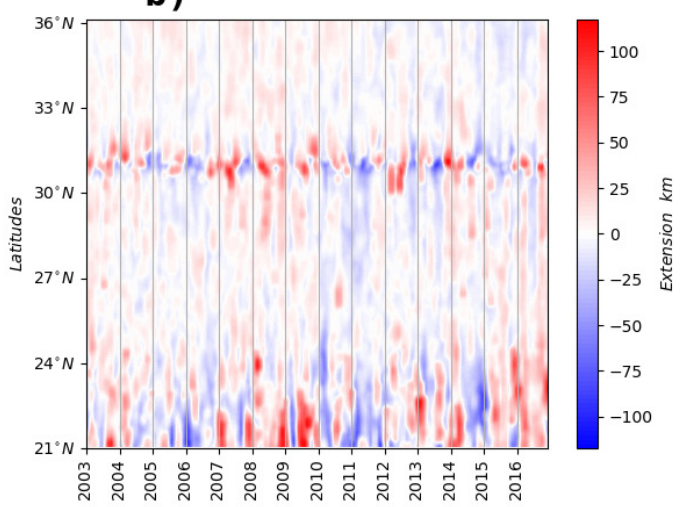

d)

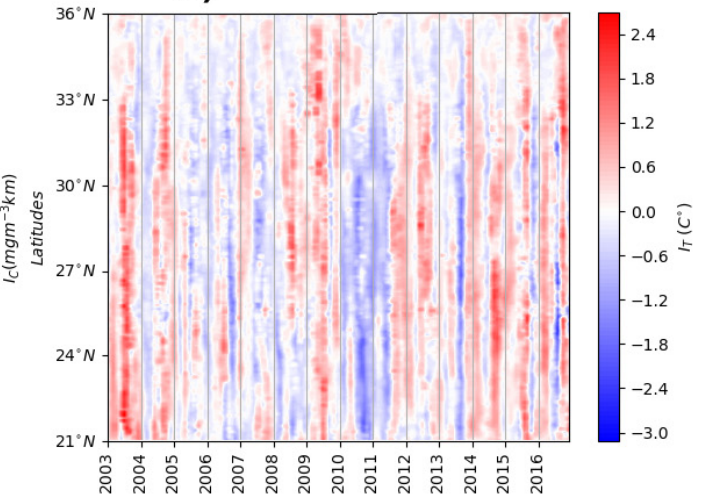

f)

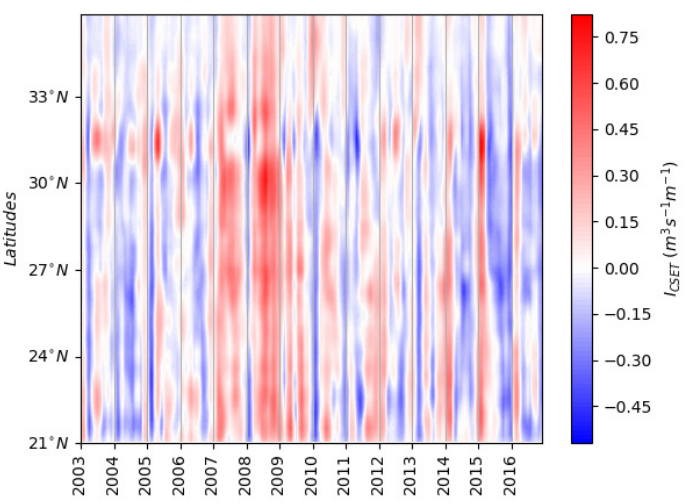

Fig. 7. Space-time Hövmoller diagram presenting anomalies of (a) upwelling extent from SST, (b) upwelling extent from CHLa, (c) upwelling index ( $I_{C}$ ) computed as the CHLa average multiplied by its extent, (d) upwelling intensity $I_{T}$, (e) eddy kinetic energy ( $\mathrm{cm}^{2} \mathrm{~s}^{-2}$ ) estimated from geostrophic velocities derived from satellite-derived sea-surface height anomalies, and (f) cross-shore Ekman transport (ICSET), over the 2003-2016 period.

The other upwelling index, related to the $\mathrm{CHL}_{\mathrm{a}}$ concentration $I_{C}$, gives another perspective on the upwelling conditions. Fig. 6(c) shows an Hövmoller diagram at 4-km/30-day spatiotemporal resolution of the $\mathrm{CHL}_{\mathrm{a}}$ index $I_{c}$. A considerable interannual and seasonal variability is observed in the $\mathrm{CHL}_{\mathrm{a}}$ index $I_{c}$ along the Moroccan coast, indicating lower phytoplankton biomass during some years (2006) and higher biomass in others (2015 and 2016). Latitudinal differences are very noticeable and low $I_{c}$ is generally featured during all years north $33^{\circ} \mathrm{N}$. Some seasonal signals are evident, where very moderate indices were observed in summer between $31^{\circ} \mathrm{N}$ and $27^{\circ} \mathrm{N}$. In contrast, the region between $21^{\circ} \mathrm{N}$ and $24^{\circ} \mathrm{N}$ displayed elevated index $I_{c}$ during most years and seasons and some of the highest values of the $\mathrm{CHL}_{\mathrm{a}}$ index along with noticeable seasonal variation compared with the other regions.
This is the largest spatial region along the Moroccan coast that appears to contain the highest contents of phytoplankton in the surface waters with the interannual variability revealing that 2016 was a particularly anomalous year.

Different upwelling indices were used to characterize the interannual variation of the upwelling dynamics. Each of the indices allows us to synthesize the studied area into different regions. However, this division is different from each index to another. Here, these divisions are different according to each index.

1) In the region north of $33^{\circ} \mathrm{N}$, all the indices suggest that this region is characterized by a weak/inexistent upwelling.

2) Cape Ghir around $31^{\circ} \mathrm{N}$ is distinguished by the existence of an oceanic plateau, which extends offshore 


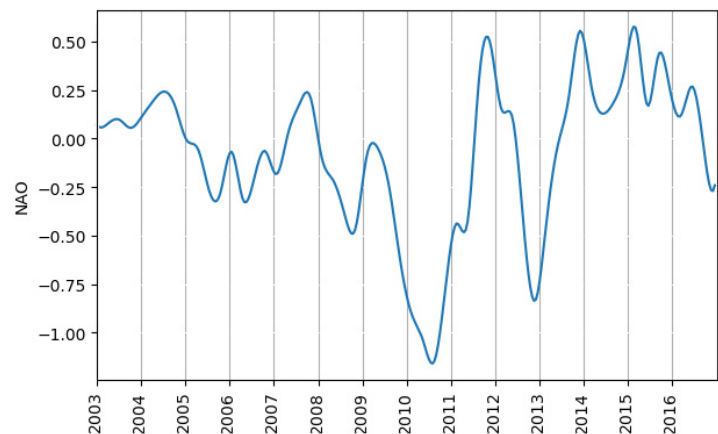

Fig. 8. North Atlantic Oscillation index from 2003 to 2016.

$(150 \mathrm{~km})$. This allows the generation of permanent coastal upwelling extent during summer and autumn [see Fig. 6(a) and (b)]. This is associated with variations of water column stratification, which influence the configuration of phytoplankton communities [see Fig. 6(c)] and an enhancement of the upwelling favorable wind [see Fig. 6(f)], which results in a stronger thermal gradient [see Fig. 6(d)].

3) The regions between $26^{\circ} \mathrm{N}$ and $31^{\circ} \mathrm{N}$, both the upwelling extent and intensity $I_{T}$, show different properties. The upwelling is intense but does not extend too much. Moreover, the upwelling seasonality is more pronounced in its intensity $I_{T}$, while no clear seasonality is recorded in its spatial distribution. The difference between the upwelling extent and the intensity is due to two different physical processes: the upwelling intensity quantifies the coastal cooling effect created by the cross-shore Ekman transport $I_{\mathrm{CSET}}$, which shares a very similar pattern with the upwelling intensity $I_{T}$ in the present region [see Fig. 6(d) and (f)]. On the other hand, the upwelling extent of the upwelled water is due to instabilities generated in the upwelling jet.

4) The southern region (between $25^{\circ} \mathrm{N}$ and $21^{\circ} \mathrm{N}$ ) is characterized by a permanent intense upwelling activity throughout the year with a wind maximum in summer and thermal peak from spring to autumn. This region shows high $\mathrm{CHL}_{\mathrm{a}}$ index $I_{c}$, with clear seasonality similar to the thermal index $I_{T}$ reaching its high values around the years' end. Instabilities generated in the upwelling jet over this region are spatially structured into filaments and eddies that remain coherent, relatively persistent, and recurrent for several weeks, resulting in high upwelling extent, penetrating up to $400-\mathrm{km}$ offshore Cape Blanc and transporting biologically important materials far into the ocean interior.

\section{CONClusion}

This article contributes to the knowledge of the spatiotemporal variability of the upwelling dynamics over the north-west African margin. Previous works have addressed the issue of the automatic identification of upwelling regions from the SST images along different parts of CCUS. However, none of the previous work has successfully been able to delineate the central part of the Canary Upwelling Ecosystem from the SST images. To the best of our knowledge, the method proposed in this article not only is the first to successfully delineate upwelling regions from the SST images over the whole Moroccan Atlantic coast but also extracts the upwelling regions from the $\mathrm{CHL}_{\mathrm{a}}$ images. The proposed method is performed in two main stages: the first one with the goal to break down the SST and $\mathrm{CHL}_{\mathrm{a}}$ images into homogeneous regions and the second step develops the simple algorithm that chooses and merges groups of pixels, which best reproduce the shape of upwelling areas. This method has shown to be very accurate in different upwelling scenarios. Previous works have addressed the spatial extent of the upwelling from biological and physical satellite observations. In this article, the biological and physical spatial extents of the upwelling are computed based on an advanced method that shows a high accuracy in terms of upwelling detection. The results show that the upwelling spatial extent patterns computed from SST and $\mathrm{CHL}_{\mathrm{a}}$ display substantially similar patterns. Moreover, the upwelling dynamics is explored throughout its spatiotemporal extents and different upwelling indices for the period between 2003 and 2016. This led us to define regions with different upwelling properties in terms of the upwelling extent and intensity.

\section{APPENDIX}

\section{A. Region-Growing}

The region-growing algorithm aims to group a set of pixels according to the criteria of homogeneity and adjacency. It analyzes the neighboring pixels of initial points and decides if the adjacent pixel must be added to the region. The pixels belonging to the same region are labeled by the same index and the pixels in other regions are labeled by a different index.

\section{B. Particle Swarm Optimization}

PSO is a stochastic optimization method inspired by birds' social behavior in a flock [31], [32]. It works by having a group of candidate solutions called particles. Each of these particles flies through the space of search according to a few simple formulas over the position and velocity of particles. Their movements are influenced by their own best known position in the space of search called $p$ best, and the best known position of the whole group called gbest [37]. After each iteration, each particle's velocity and positions is recomputed with following equation:

$$
\begin{aligned}
v_{i}(t+1)= & \omega v_{i}(t)+c_{1} r_{1}(t)\left(p_{i}(t)-x_{i}(t)\right) \\
& +c_{2} r_{2}(t)\left(\hat{p}(t)-x_{i}(t)\right) \\
x_{i}(t+1)= & x_{i}(t)+v_{i}(t+1) .
\end{aligned}
$$

$\omega$ presents the inertia weight, which controls the influence of the previous velocity; a large inertia weight favors exploration, while a small inertia weight favors exploitation [37]. $c_{1}$ and $c_{2}$ present constants of acceleration, $v_{i}$ is the particle's velocity, $x_{i}(t)$ is the particle's time-position, and $p_{i}(t)$ and $\hat{p}_{i}(t)$ are the $p$ best and $g$ best as stated before. $r_{1}$ and $r_{2}$ are the vectors with their elements sampled from a uniform distribution $U(0,1)$

The cognitive component $p_{i}(t)-x_{i}(t)$ serves as a memory of previous particles' best positions, while the social component $\hat{y}(t)-x_{i}(t)$ gives the whole group's belief as to where the best solution is. 
PSO's efficiency is sensitive to the parameters $\omega, c_{1}$ and $c_{2}$. While several suggestions (based on empirical studies) for good values can be found in the literature, such as in [38], the PSO exhibits a convergent behavior if the following condition is satisfied:

$$
\omega>\frac{1}{2}\left(c_{1}+c_{2}\right), \quad \omega<1
$$

if not the PSO exhibits a cyclic or divergent behavior.

\section{PSO Clustering Algorithm}

Within the framework of pixel clustering, each particle $x_{i}$ is structured as $x_{i}=\left(m_{i 1}, \ldots, m_{i j}, \ldots, m_{i N c}\right)$, where $m_{i j}$ is the $j$ th cluster centroid vector of the $i$ th particle. Thus, a swarm reflects a number of candidate pixel clusterings. The fitness function is used to evaluate each particle as

$$
f\left(x_{i}, Z_{i}\right)=\omega_{1} \bar{d}_{\max }\left(Z_{i}, x_{i}\right)+\omega_{2}\left(z_{\max }-d_{\min }\left(x_{i}\right)\right)
$$

where $z_{\max }$ is the highest value in the image and $Z_{i}$ is the matrix that assigns each pixel to clusters of particle $i$. Each element $z_{i j p}$ decides if a pixel $z_{p}$ belongs to a cluster $C_{i j}$ of a particle $i$. The constants $\omega_{1}$ and $\omega_{2}$ are user-defined constants.

The following equation presents the highest average Euclidean distance between all classes and their associated particles, with $\left|C_{i j}\right|$ presenting the cardinality of the set $C_{i j}$ :

$$
\bar{d}_{\max }\left(Z_{i}, x_{i}\right)=\max _{j=1, \ldots . N_{c}}\left\{\sum_{\forall z_{p} \in C_{i j}} \frac{d\left(z_{p}, m_{i j}\right)}{\left|C_{i j}\right|}\right\} .
$$

The following equation presents the lowest Euclidean distance between any pair of centroids:

$$
d_{\min }\left(x_{i}\right)=\min _{\forall j_{1}, j_{2}, j_{1} \neq j_{2}}\left\{d\left(m_{i j_{1}}, d_{i j_{2}}\right)\right\} .
$$

This fitness function is multiobjective and it is designed to hold the following.

1) Reduce the distance between cluster centroid and its associate pixels, as quantified by $\bar{d}_{\max }(Z i, x i)$.

2) Increase the distance between any pair of centroids, as quantified by $d_{\min }\left(x_{i}\right)$.

The PSO-based clustering method can be summarized as in Algorithm 1.

Compared with the FCM algorithm, this approach minimizes the impact of initial conditions. Moreover, an advantage of this method is that an optimal clustering search is performed in parallel.

\section{Fuzzy c-Means}

The FCM algorithm attempts to partition a finite collection of $n$ pixels $X=\left\{x_{1}, \ldots, x_{n}\right\}$ into a collection of $c$ fuzzy clusters with respect to some given criterion. Given a finite set of pixels, the algorithm returns a list of $c$ cluster centers $C=\left\{c_{1}, \ldots, c_{c}\right\}$ and a fuzzy partition matrix, which presents the degree of belonging for each pixel $x_{k}$ to a given cluster $c_{i}$. The FCM algorithm is applied to minimize an objective function called c-means functional

$$
J_{m}(X ; U, V)=\sum_{k=1}^{n} \sum_{i=1}^{c}\left(\mu_{i k}\right)^{m}\left\|x_{k}-v_{i}\right\|^{2}
$$
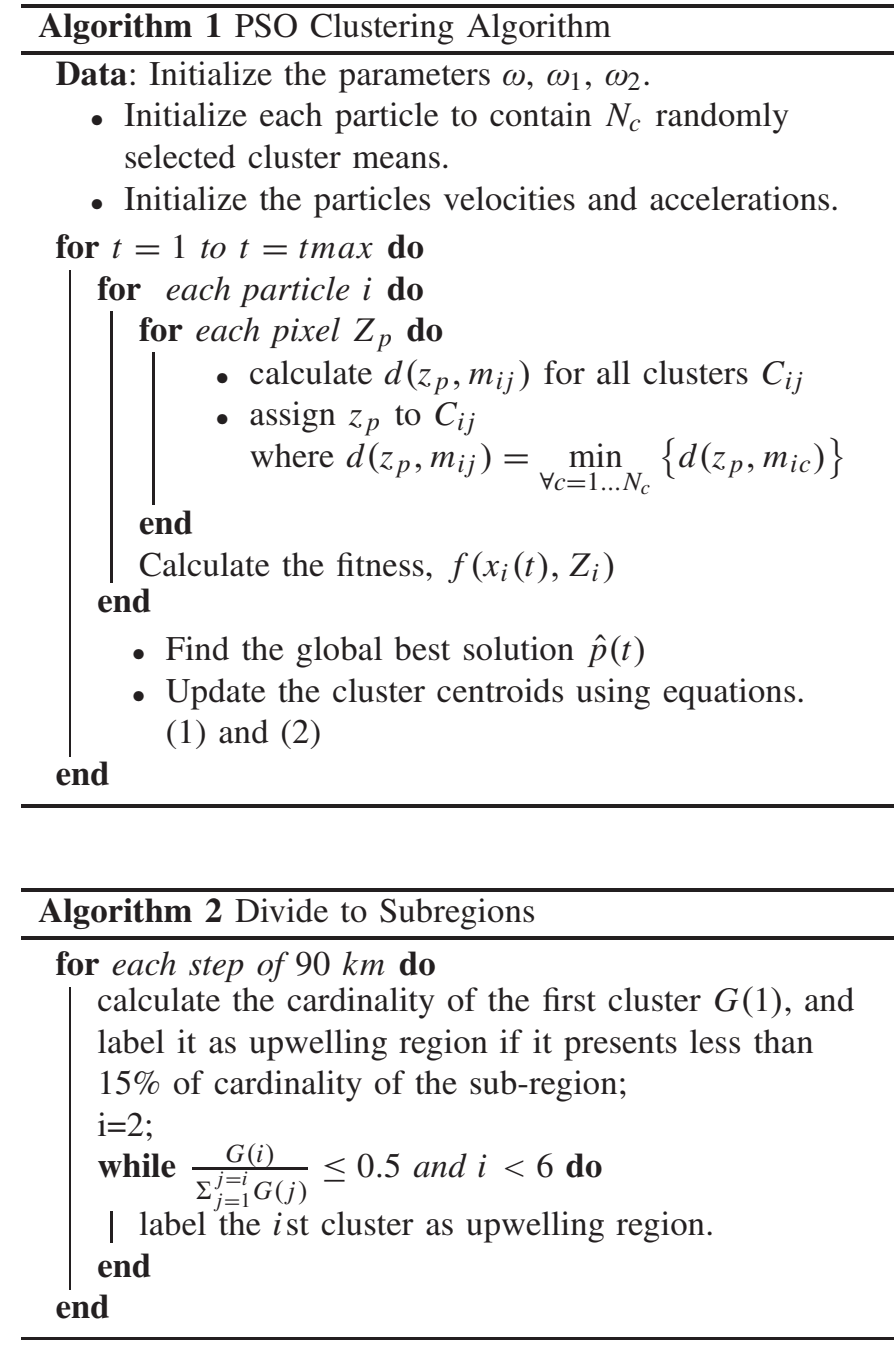

where $n$ is the length of the vector $X$ presenting pixels of a given SST image. $V=\left\{v_{1}, v_{2}, \ldots, v_{n}\right\}$ is the vector of cluster prototypes and $U=\left[\mu_{i k}\right]$ is the fuzzy partition matrix, which presents the degree of belonging for each pixel $x_{k}$ to a given cluster $c_{i}$. The weighting exponent $m$ controls the fuzziness of membership values, which vary in the interval $[1, \infty]$. An increase in $m$ leads to an increase in fuzziness partitions.

The objective function [see (10)] can be seen as a measure of the total variance of $x_{k}$ from $v_{i}$. The minimization of the objective function [see (10)] represents a nonlinear optimization problem that can be solved by using, respectively, the following cluster centroids and membership functions:

$$
\begin{aligned}
v_{i} & =\frac{\sum_{k=1}^{n}\left(\mu_{i k}^{m}\right) x_{k}}{\sum_{k=1}^{n}\left(\mu_{i k}^{m}\right)}, \quad 1 \leq i \leq c \\
\mu_{i k} & =\frac{1}{\sum_{j=1}^{c}\left(\frac{\left\|x_{k}-v_{i}\right\|}{\left\|x_{k}-v_{j}\right\|}\right)^{\frac{2}{(m-1)}}}, \quad 1 \leq i \leq c, 1 \leq k \leq n .
\end{aligned}
$$


The goal here is to iteratively improve a sequence of sets of fuzzy clusters through those equations until no further improvement is possible for the objective function.

\section{REFERENCES}

[1] M.-E. Carr and E. J. Kearns, "Production regimes in four eastern boundary current systems," Deep Sea Res. II, Top. Stud. Oceanogr., vol. 50, nos. 22-26, pp. 3199-3221, 2003.

[2] M. A. A. Jeyid, "Relations environnement et évolution spatio-temporelle des petits poissons pélagiques dans le système d'upwelling de la zone NW Africaine,' Ph.D. dissertation, Lab. Oceanol. Geosci., Littoral Univ., Dunkirk, France, 2016.

[3] A. Benazzouz et al., "An improved coastal upwelling index from sea surface temperature using satellite-based approach-The case of the Canary Current upwelling system," Continental Shelf Res., vol. 81, pp. 38-54, Jun. 2014.

[4] A. Bakun, "Coastal upwelling indices, west coast of North America," U.S. Dept. Commerce, NOAA, Silver Spring, MD, USA, Tech. Rep. NMFSSSRF671, 1973.

[5] V. W. Ekman, "On the influence of the Earth's rotation on oceancurrents," Ark. Mat. Astron. Fys., vol. 2, pp. 1-53, May 1905

[6] W. S. Wooster, A. Bakun, and D. R. McLain, "Seasonal upwelling cycle along the eastern boundary of the north Atlantic," J. Marine Res., vol. 34, no. 2, pp. 131-141, 1976.

[7] J. Marcello, A. Hernández-Guerra, F. Eugenio, and A. Fonte, "Seasonal and temporal study of the northwest African upwelling system," Int. J. Remote Sens., vol. 32, no. 7, pp. 1843-1859, 2011.

[8] A. Benazzouz, H. Demarcq, and G. González-Nuevo, "Recent changes and trends of the upwelling intensity in the canary current large marine ecosystem," in Proc. Oceanographic Biol. Features Canary Current Large Marine Ecosyst., 2015, pp. 321-330.

[9] K. Nieto, H. Demarcq, and S. McClatchie, "Mesoscale frontal structures in the canary upwelling system: New front and filament detection algorithms applied to spatial and temporal patterns," Remote Sens. Environ., vol. 123, pp. 339-346, Aug. 2012.

[10] S. Nascimento, P. Franco, F. Sousa, J. Dias, and F. Neves, "Automated computational delimitation of SST upwelling areas using fuzzy clustering," Comput. Geosci., vol. 43, pp. 207-216, Jun. 2012.

[11] F. M. Sousa, S. Nascimento, H. Casimiro, and D. Boutov, "Identification of upwelling areas on sea surface temperature images using fuzzy clustering," Remote Sens. Environ., vol. 112, no. 6, pp. 2817-2823, 2008.

[12] A. Tamim et al., "A simple and efficient approach for coarse segmentation of moroccan coastal upwelling," in Proc. 21st Eur. Signal Process. Conf. (EUSIPCO), Sep. 2013, pp. 1-5.

[13] A. Tamim, K. Minaoui, K. Daoudi, A. Atillah, H. Yahia, and D. Aboutajdine, "Upwelling detection in SST images using fuzzy clustering with adaptive cluster merging," in Proc. ISIVC, 2014, pp. 1-5.

[14] A. Tamim, K. Minaoui, K. Daoudi, H. Yahia, A. Atillah, and D. Aboutajdine, "An efficient tool for automatic delimitation of moroccan coastal upwelling using SST images," IEEE Geosci. Remote Sens. Lett., vol. 12, no. 4, pp. 875-879, Apr. 2015.

[15] V. Rossi, C. López, J. Sudre, E. Hernández-García, and V. Garçon, "Comparative study of mixing and biological activity of the Benguela and Canary upwelling systems," Geophys. Res. Lett., vol. 35, no. 11, Jun. 2008. doi: 10.1029/2008GL033610.

[16] A. El Aouni, K. Daoudi, H. Yahia, K. Minaoui, and A. Benazzouz, "Surface mixing and biological activity in the North-West African upwelling," Chaos, Interdiscipl. J. Nonlinear Sci., vol. 29, no. 1, 2019, Art. no. 011104.

[17] C. Lathuilière, V. Echevin, and M. Lévy, "Seasonal and intraseasonal surface chlorophyll-a variability along the Northwest African coast," J. Geophys. Res., Oceans, vol. 113, no. C5, May 2008. doi: 10.1029/2007JC004433.

[18] Y. Pradhan, S. J. Lavender, N. J. Hardman-Mountford, and J. Aiken, "Seasonal and inter-annual variability of chlorophyll-a concentration in the Mauritanian upwelling: Observation of an anomalous event during 1998-1999," Deep Sea Res. II, Top. Stud. Oceanogr., vol. 53, nos. 14-16, pp. 1548-1559, 2006.

[19] J. Arístegui and M. F. Montero, "Temporal and spatial changes in plankton respiration and biomass in the Canary Islands region: The effect of mesoscale variability," J. Marine Syst., vol. 54, nos. 1-4, pp. 65-82, 2005.

[20] M. Menna et al., "Upwelling features off the coast of North-Western Africa in 2009-2013," Bollettino di Geofisica Teorica ed Applicata, vol. 57, no. 1, pp. 71-86, 2016.
[21] H. Demarcq, R. Barlow, and L. Hutchings, "Application of a chlorophyll index derived from satellite data to investigate the variability of phytoplankton in the Benguela ecosystem," Afr. J. Marine Sci., vol. 29, no. 2, pp. 271-282, 2007.

[22] S. Nixon and A. Thomas, "On the size of the Peru upwelling ecosystem," Deep Sea Res. I, Oceanographic Res. Papers, vol. 48, no. 11, pp. 2521-2528, 2001.

[23] I. M. Belkin and J. E. O'Reilly, "An algorithm for oceanic front detection in chlorophyll and SST satellite imagery," J. Marine Syst., vol. 78, no. 3, pp. 319-326, 2009.

[24] A. Tamim, K. Minaoui, K. Daoudi, A. Atillah, and D. Aboutajdine, "On detectability of moroccan coastal upwelling in sea surface temperature satellite images," in Proc. Int. Symp. Vis. Comput. New York, NY, USA: Springer, 2014, pp. 386-395.

[25] A. Tamim et al., "A simple tool for automatic extraction of Moroccan coastal upwelling from Sea Surface Temperature images," in Proc. 9th Int. Conf. Intell. Syst., Theories Appl. (SITA), May 2014, pp. 1-4.

[26] J. Sudre, C. Maes, and V. Garçon, "On the global estimates of geostrophic and Ekman surface currents," Limnol. Oceanogr., Fluids Environ., vol. 3, no. 1, pp. 1-20, 2013.

[27] Y.-L. Chang and X. Li, "Adaptive image region-growing," IEEE Trans. Image Process., vol. 3, no. 6, pp. 868-872, Nov. 1994.

[28] U. Kaymak and M. Setnes, "Fuzzy clustering with volume prototypes and adaptive cluster merging," IEEE Trans. Fuzzy Syst., vol. 10, no. 6, pp. 705-712, Dec. 2002.

[29] H. Frigui and R. Krishnapuram, "A robust algorithm for automatic extraction of an unknown number of clusters from noisy data," Pattern Recognit. Lett., vol. 17, no. 12, pp. 1223-1232, 1996.

[30] E. Backer and A. K. Jain, "A clustering performance measure based on fuzzy set decomposition," IEEE Trans. Pattern Anal. Mach. Intell., vol. PAMI-3, no. 1, pp. 66-75, Jan. 1981.

[31] J. Kennedy, "Particle swarm optimization," in Encyclopedia of Machine Learning. New York, NY, USA: Springer, 2011, pp. 760-766.

[32] J. Kennedy, J. F. Kennedy, R. C. Eberhart, and Y. Shi, Swarm Intelligence. San Mateo, CA, USA: Morgan Kaufmann, 2001.

[33] I. Alvarez, M. Gomez-Gesteira, M. deCastro, J. L. Gomez-Gesteira, and J. M. Dias, "Summer upwelling frequency along the western Cantabrian coast from 1967 to 2007," J. Mar. Syst., vol. 79, nos. 1-2, pp. 218-226, 2010.

[34] M. Gómez-Gesteira, M. deCastro, M. N. Lorenzo, I. Alvarez, and A. J. C. Crespo, "Influence of atmospheric modes on coastal upwelling along the western coast of the iberian peninsula, 1985 to 2005," Climate Res., vol. 36, no. 2, pp. 169-179, 2008.

[35] D. W. J. Thompson, J. M. Wallace, and G. C. Hegerl, "Annular modes in the extratropical circulation. Part II: Trends," J. Climate, vol. 13, no. 5, pp. 1018-1036, 2000.

[36] A. G. Kostianoy and A. G. Zatsepin, "The West African coastal upwelling filaments and cross-frontal water exchange conditioned by them," J. Mar. Syst., vol. 7, nos. 2-4, pp. 349-359, 1996.

[37] Y. Shi and R. C. Eberhart, "Parameter selection in particle swarm optimization," in Proc. Int. Conf. Evol. Program. New York, NY, USA: Springer, 1998, pp. 591-600.

[38] F. van den Bergh, "An analysis of particle swarm optimizers," Ph.D. dissertation, Dept. Natural Agricult. Sci., Univ. Pretoria, Pretoria, South Africa, 2006.

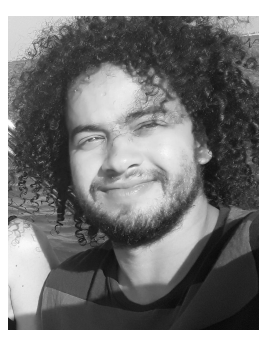

Anass El Aouni received the Ph.D. degree in applied mathematics and scientific computing from the University of Bordeaux (INRIA), Bordeaux, France, in 2019, and the Ph.D. degree in computer science from Mohammed V University, Rabat, Morocco, in 2019.

He is currently a Post-Doctoral Fellow with INRIA of Grenoble, Montbonnot-Saint-Martin, France. His research interests include nonlinear fluid dynamics, physical oceanography, turbulence, vortex dynamics, lagrangian coherent structures, and image and nonlinear signal processing in oceanography. 


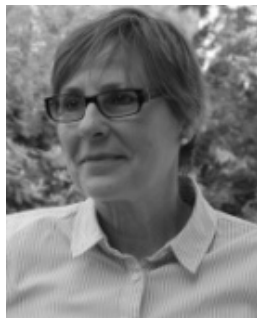

Véronique Garçon received the Ph.D. degree in environmental sciences from the University of Paris VII, Paris, France, in 1981

She was recruited as an Early Career Scientist with the Centre National de la Recherche Scientifique (CNRS), Paris, in 1985. She was a Habilitation à Diriger des Recherches, Toulouse, in 1995. She was with the Institut de Physique du Globe de Paris, Paris, and then moved to Toulouse with a sabbatical stay at Princeton University, Princeton, NJ, USA, from 1995 to 1996. She became a Post-Doctoral Fellow with the Massachusetts Institute of Technology (MIT), Cambridge, MA, USA. She is currently a CNRS Senior Scientist with LEGOS, Toulouse, France. She has supervised $17 \mathrm{Ph} . \mathrm{D}$. students and 18 post-doctoral fellows. She has published more than 110 scientific articles in peer-reviewed journals. Her research themes aim toward understanding and quantifying processes governing fluxes of carbon, oxygen and associated biogeochemical elements in the ocean, using in situ observations, remotely sensed data, coupled physical biogeochemical modeling, and data assimilation technics.

Ms. Garcon is a member of the Global Ocean Oxygen Network from IOCUNESCO GO2NE and the French IFREMER Scientific Committee for ten years, and in many national (CNRS, French Navy, and so on), European (ESF, EC, EGU, and ERC), and International Scientific Instances. She is also a member of the IOCCP SSG and the GBC-GOOS panel. She received the Anton Bruun Medal in June 2017 from IOC-UNESCO. She served in the JGOFS SSC. She served as the SOLAS Chair from 2015 to 2018 and the Co-Chair for the VOICE/IMSOO/GOOS initiative.

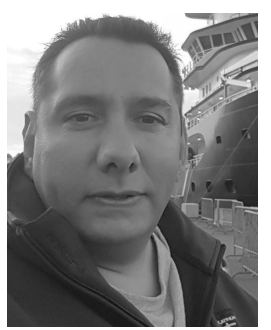

Joël Sudre received the Ph.D. degree in physical oceanography from Paul Sabatier University, Toulouse, France, in 2013.

$\mathrm{He}$ is currently a French National Centre for Scientific Research (CNRS) Engineer with the Complex Coupled Systems (SYSCO2) Team, Laboratoire d'Etudes en Géophysique et Océanographie Spatiales, Toulouse. He is also a Technical Representative with the National Institute for Earth Sciences and Astronomy/CNRS and the French Ocean Data Information and Service, Toulouse. He has authored or coauthored 39 publications in international peer-reviewed journals. His research interests include physical and dynamical oceanography, image processing for oceanographic studies, and in situ and satellite ocean observing systems.

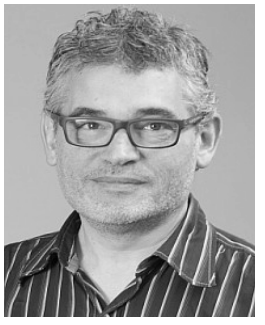

Hussein Yahia received the Doctorat de 3eme cycle degree from the University of Paris-Sud, Orsay, France, in 1987, and the Habilitation à Diriger des Recherches (HDR) degree from Paris 13 University, Villetaneuse, France, in 2003.

$\mathrm{He}$ is currently the Head of the Geostat (Geometry and Statistics in Acquisition Data) Research Team with the French National Public Research Institute in Computer Science and Applied Mathematics (INRIA), Rocquencourt, France. He is also involved in many national, European, and international contracts, in particular with the French Spatial Agency (Centre National d'Etudes Spatiales) and the European Spatial Agency. He has been supervising over 12 Ph.D. students. He specializes in the analysis of complex signals and systems using ideas and paradigms from statistical physics, and sparsity, compact representations, multiresolution analysis, and optimal inference along the scales of complex signals. He has authored or coauthored more than 90 publications in international peer-reviewed top journals and conferences.

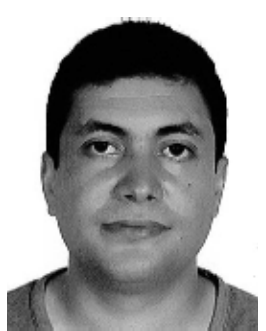

Khalid Daoudi received the master's and Ph.D. degrees in applied mathematics from University Paris 9 Dauphine, Paris, France, in 1993 and 1996, respectively. His Ph.D. dissertation was prepared at the Fractals Group, INRIA, Rocquencourt, France.

In 1997, he held a post-doctoral position at the Department of Mathematics, Ecole Polytechnique de Montréal, Montreal, QC, Canada. From December 1997 to July 1999, he held a post-doctoral position at the Stochastic Systems Group (SSG), Laboratory for Information and Decision Systems (LIDS), Massachusetts Institute of Technology (MIT), Cambridge, MA, USA. Since October 1999, he has held a permanent position with the Speech Group, INRIA, Lorraine, France. From October 2003 to February 2009, he was on leave at CNRS with the SAMOVA team of IRIT, Toulouse. Since March 2009, he has been with GeoStat Team, INRIA Bordeaux, Talence. His research interests include statistical learning, multiscale signal/image processing, speech processing, and pathological voice analysis (particularly neurodegenerative)

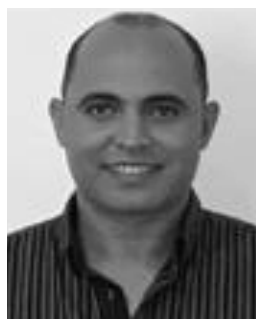

Khalid Minaoui received the dual national $\mathrm{Ph} . \mathrm{D}$. degree (cotutelle) in signal processing and computer science from Mohammed V University, Rabat, Morocco, and Telecom Bretagne, Brest, France, in 2010, and the Habilitation à Diriger des Recherches (HDR) degree from Mohammed V University in 2014.

$\mathrm{He}$ is currently a Professor with the Faculty of Sciences of Rabat, Mohammed V University. His research interests are signal processing and applications. 